Journal of Teacher Education for Sustainability, vol. 16, no. 2, pp. 5-17, 2014

\title{
Interplay of Rhizome and Education for Sustainable Development
}

\author{
Tanja Tillmanns \\ Dublin City University, Ireland \\ Charlotte Holland \\ Dublin City University, Ireland \\ Francesca Lorenzi \\ Dublin City University, Ireland \\ Pierre McDonagh \\ University of Bath, the United Kingdom
}

\begin{abstract}
One of the central challenges within education for sustainable development (ESD) is in empowering learners to reframe mindsets, particularly those that result in unsustainable behaviours and/or actions. This paper introduces the concept of rhizome articulated by Deleuze and Guattari (1987) and proposes that it can act as a framework for re-conceptualising processes of ESD. Key constructs within the rhizome, such as assemblages, nomadism, war machines and lines of flights, are discussed to highlight their relevance to ESD. The principles of the rhizome (connection, heterogeneity, multiplicity, signifying rupture, cartography and decalcomania) are then examined in the context of six processes necessary for effective ESD outlined by Tilbury (2011), namely, collaboration, dialogue, 'whole system' engagement, innovation within curricula, teaching and learning and active and participatory learning. The final section critically considers how this weaving of rhizomatic principles with the processes of ESD impacts on educating for sustainability. The rhizome has the potential to inspire educators and learners alike to become more critically aware of the interconnectivity and disruptive influences within sustainability. In this regard, the discussion ends by concluding that the reconceptualisation of ESD as rhizome or rhizomatic can foster an ontological shift towards perceiving the nature of reality as complex interconnected multiplicities.
\end{abstract}

Keywords: rhizome, processes of education for sustainable development, sustainability, self, ontology 


\section{Rhizome}

One of the central challenges within ESD is in empowering learners to reorient their frames of mind, particularly those that result in unsustainable behaviours and/or actions. The concept of rhizome, articulated by Deleuze and Guattari (1987), is utilised in this discussion to re-conceptualise the processes of education for sustainable development (ESD). So, what is the rhizome?

From a botanical perspective, a rhizome is a horizontal, non-hierarchical root system (Figure 1). An examination of the botany of the rhizome reveals a root system that contains various points; that sometimes interconnect with other root formations, other

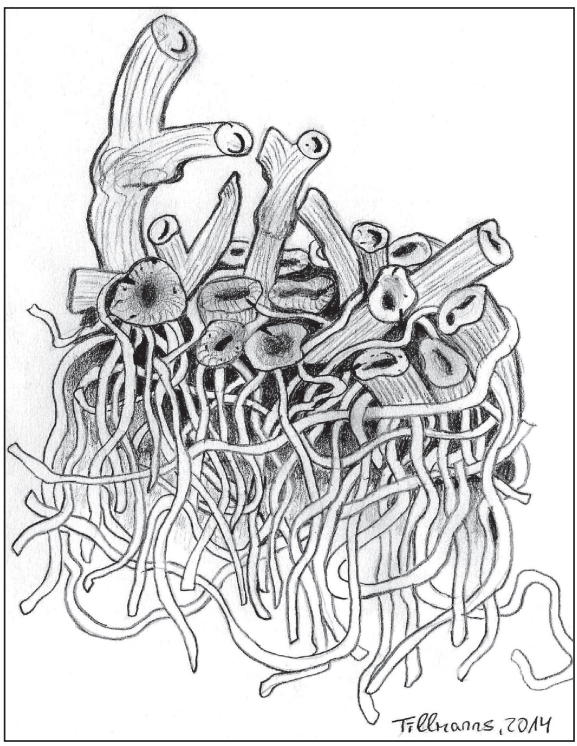

Figure 1. A botanical representation of a rhizome times simply form an end-point for that part of the root. Therefore, the rhizome sometimes forms multiplicities (of roots), which, in turn, can themselves change, multiply or divide into other roots through complex encounters across the entire rhizome root system (Deleuze \& Guattari, 1987).

From a philosophical perspective, Deleuze and Guattari (1987) perceive the rhizome as a 'collective' of ever changing, interconnecting multiplicities, with no central control system, which acts as an inspiration for re-conceptualising the nature of reality. The rhizomatic view of the world considers the whole inextricable combination of interrelated assemblages of individuals and groups and includes: humans, non-humans, material resources, non-material resources. In this regard, the rhizome offers a novel way of perceiving our world and, in doing so, enables us to consider the interconnection of knowledge construction, society, culture, attitudes and/or values.

The rhizomatic perception of reality elucidated by Deleuze and Guattari is offered as a viable alternative to more traditional, arborescent modes of conceiving and understanding our world. The arborescent or tree-like view of reality tends to rely on hierarchical understandings of our world. Such hierarchical understandings are characterised by a universal acceptance of the processes of segmenting our world into discrete entities, to which fixed meanings are attributed. The rhizome offers a means to move away from traditional and hierarchical frames of thinking as it promotes multi-perspectivity of 'being and becoming'. The rhizome captures complexity and generates a fluidity that facilitates re-orientation of mindsets towards greater sustainability and harmony with the world we live in. For this reason, a rhizomatic view of ESD can make a positive contribution in enabling the reorientation of thinking and practices towards the sustainment of all living and non-living entities within our biosphere.

A rhizomatic view of ESD perceives sustainability education as distributed, interconnected, co-constructed and emancipatory through educational processes involving critical consideration of the complex interplay of human and non-human entities. The 
rhizome can thus be considered within the context of ESD as the on-going transformation of self, as a fertile milieu for continuous 'becomings' for the learner. The process of ESD, when evaluated in rhizomatic terms, involves mapping the multiple ways key sustainability concepts, attitudes and dispositions present and develop in the mindset of learners. Furthermore, within the context of education for sustainability, consideration of the extent of rhizomatic inter-connectedness leads to "alternative ways of knowing and being which include indigenous ones” (Le Grange, 2011, p. 744).

The ensuing discussion begins by outlining key constructs within the rhizome, namely, assemblages, nomadism, war machines and lines of flights, and discusses the relevance of these to ESD. The principles of the rhizome - connection, heterogeneity, multiplicity, signifying rupture, cartography and decalcomania - are then examined in the context of six processes necessary for effective ESD outlined by Tilbury (2011) collaboration, dialogue, 'whole system' engagement, innovation within curricula, teaching and learning and active and participatory learning. The final section critically considers how this weaving of rhizomatic principles with the processes of ESD impacts on educating for sustainability.

\section{Constructs of the Rhizome}

The key constructs within the rhizome are: assemblages, nomadism, war machines and line of flights.

\section{Assemblages}

The rhizome, in its botanical form, consists of assemblages of roots and root systems, connected through unstructured root developments. In philosophical terms, the rhizomatic view of the world entails assemblages of individual/s, groups - human, non-human, material or non-material. Assemblages are perceived not from an insider-lookingoutwards lens of our world, but rather from a meta-level perspective (outsider-lookinginwards) that considers the whole inextricable combination of interrelated parts (Deleuze \& Guattari, 1987) or as wholes identified by relations of exteriority (DeLanda, 2006). Assemblages are multi-scaled, emerging at every level of the rhizome. They contain multiplicities and can indeed become further multiplicities when they connect with other assemblages. The components that form assemblages can be simultaneously part of other assemblages (DeLanda, 2006). For instance, sustainability as an assemblage consists of multiplicities, to name a few: nature, cultures, science, technology, economy, politics, conflict and peace, health, social justice, emotions, desires, interests and needs. However, economy and technology, for instance, can also be constituents of a 'knowledge economy' assemblage.

Assemblages present two dimensions corresponding to the characteristics of the multiplicities that form assemblages. Deleuze and Guattari (1987) elaborate that:

On a first, horizontal, axis, an assemblage comprises two segments, one of content the other of expression [...] Then on a vertical axis, this assemblage has both territorial sides, or reterritorialized sides, which stabilise it, and cutting edges of deterritorialization, which carry it away (p. 88). 
DeLanda's (2006) interpretation defines the horizontal axis as variable roles of an assemblage's component and defines the vertical axis as variable processes of components. The extremes of the horizontal axis are either purely material or purely expressive. By nature, a component may be a mixture of material and expressive roles, exercising different sets of capacities (DeLanda, 2006).

A pertinent example to illustrate these key dimensions of an assemblage would be an educational intervention within a school setting. The material/content role in an educational context can be simply the classroom materials, the physical interior of classroom, buildings or indeed the trees on campus. A teaching context can demonstrate an expressive role of assemblage components. The way in which the curriculum is delivered and/or the tone, body language, attitude, emotions of the educators, as well as the students' attitudes, attention and responses during the class, all form expressive roles of the assemblage.

The vertical axis or the variable processes of assemblage components (DeLanda, 2006),

either stabilise [processes of territorialization] the identity of an assemblage, by increasing its degree of internal homogeneity or the degree of sharpness of its boundaries, or destabilise it [processes of deterritorialization] (p. 12).

The processes of territorialisation stabilise and define territories (such as an educational institution's identity), while also sharpening the spatial boundaries of it - for instance, single gender schools increase the homogeneity through exclusion of the opposing gender. At university level, on the one hand, internationalisation can be seen as a process of deterritorialisation, which results in an increased heterogeneity of educational institutions achieved through the augmented presence of various cultures and ethnic groups. On the other hand, information and communication technologies illustrate a destabilisation of the boundaries of formal educational institutions through distant learning and online courses. Le Grange (2011) elucidated that

sustainability education has become territorialised into a global discourse, but the global discourse is also deterritorialised resulting in reterritorialisation occurring in local contexts (p. 746).

In other words, ESD has become territorialised on a global scale but also stabilised through identified competencies, learning and teaching approaches as well as processes. On the one hand, ESD represents a common identity with spatial boundaries, which has, for instance, been identified by Wals (2012) in his report on monitoring and evaluation of the United Nations Decade of Education for Sustainable Development (DESD) in 2012. On the other hand, the suggested whole institution approaches deterritorialise the global discourse and the identity of ESD as they call for different learning, teaching and research and a university-community network that brings about change (Wals, 2012). As a result, reterritorialisation is taking place in local contexts of educational institutions, inspired by whole-institution approaches experimenting with alternatives that are suitable for their specific context. Educational institutions need to find a different purpose to be able to connect with communities, acting as open ESD resource hubs (Wals, 2014) and sharing experiences and knowledge globally. 


\section{Nomadism and War Machine}

Deleuze and Guattari (1987) refer to nomadism as a way of becoming that is contrary to being and that resists the types of centralisation promoted through capitalist models. Nomads "exist only in becoming and in interaction" (Deleuze and Guattari, 1987, p. 430). Nomadism can be associated with free spaces for thinking. Nomads think without limits or boundaries and, in the process, generate creative and imaginative frames of thinking. Imaginative frames of thinking allow for the emergence of a war machine - which is " a war of becoming over being [...] becoming different, to think and act differently" (Deuchars, 2011, p. 2885), invented by the nomads and exterior to the State. In turn, the war machine is "an assemblage that makes thought itself nomadic" (Deleuze and Guattari, 1987 p. 4) and is the condition of creative change. The function of the war machine assemblage is to oppose dominating forms of state and capital; thus to resist control and the various kinds of power of the state (Deleuze \& Guattari, 1987). Deleuze and Guattari (1987) state, “... war machines have a power of metamorphosis, which of course allows them to be captured by States, but also to resist the capture and rise up again in other forms" (p. 437). As war machines can trigger substantial transformation and change, they carry the potential of being an icon of emancipation and creative change within ESD, specifically in terms of shifting neo-liberal type ontologies and resisting the global capitalist power of the state.

\section{Lines of Flight}

War machines can exist in diverse forms such as frames of mind and free movements. However, such movements or innovations can only be realised along 'line of flights' (Deleuze \& Guattari, 1987). A key construct within the rhizome is the "line of flight". Lines of flight are acts of deterritorialisation or processes of creation.

The assemblage that draws lines of flight is [...] of the war machine type (pp. 229). D[eterritorialization] is absolute when it [...] brings about the creation of a new earth, in other words, when it connects lines of flight (Deleuze \& Guattari, 1987, p. 510)

Lines of flight are the enactment of actions that can re-define whole societies, but can only emerge through the existence of a war machine. They can lead whole societies, groups or individuals to either achieve their maximum potential or to face the greatest dangers. In this respect, Deleuze and Guattari (1987) note the potential for global change through these lines of flight, "... the earth asserts its own powers of deterritorialisation, its lines of flight, its smooth spaces that live and blaze their way for a new earth" (p. 423). A creative line of flight can transform something into something else. This may mean progressing a social movement or the transformation of the mind-set of an individual. Lines of flight thus open up other territories of living and, in doing so, generate opportunities to foster alternative ways of thinking (Avolos \& Winslade, 2010).

A line of flight is a rupture with unexpected potential or indeed dangers and leads to new assemblages. It emerges from transformative moments or experiences that lead to shifts in frames of mind. The transformative experience of 'lines of flight' offers much hope in ESD, precisely because of its potential in reorienting learners' ways of thinking and acting. 


\section{Aligning Processes of ESD with Rhizomatic Principles}

The principles of the rhizome - connection, heterogeneity, multiplicity, signifying rupture, cartography and decalcomania - are now examined in the context of six processes necessary for effective ESD outlined by Tilbury (2011) - collaboration, dialogue, 'whole system' engagement, innovation within curricula, teaching and learning, active and participatory learning. The purpose of drawing connections between processes of ESD and rhizomatic principles is not to be prescriptive or to follow a hierarchical, topdown, instrumental approach, but rather to stimulate critical thought on perceptions of reality, teaching methods, mindsets and/or institutional processes inter alia rhizomatic principles. Therefore, the following discourse sets out to explore the potential of rhizomatic principles for ESD contexts, with a specific focus on their capacity to enable shifts in ontologies and to serve as an inspiration for educators and learners to grasp, rethink and/or re-imagine ESD.

\section{Collaboration and Dialogue, Connection and Heterogeneity}

In this section, the ESD processes of collaboration and dialogue (Tilbury, 2011) are aligned with the rhizomatic principles of connection and heterogeneity (Deleuze \& Guattari, 1987). The rhizomatic principles of connection and heterogeneity highlight the importance of maximal connections across assemblages and the creation of dialogues based on global outlooks (Nikolopoulou, 2010). Sustainability appears in diverse disciplines and entails an array of distinct concepts and advocates from different disciplines and from different contexts (Escrigas, Granados Sanchez, Hall, \& Tandon, 2014). Therefore, as outlined by Tilbury (2011), processes of collaboration and dialogue need to be encouraged among educators and learners in order to foster trans-disciplinary understandings of sustainability within ESD. This involves valuing differing perspectives from various disciplines, universities, business, governments, civil society and communities across regions and on a global scale. It also calls upon intercultural (Tilbury, 2011) and intergenerational dialogues. Collaborations with areas of art, sport, literature, fashion, culinary, media etc. (as promoted by Barber and Rousseau in 2013) would enhance heterogeneity within ESD. Furthermore, indigenous peoples, contexts and 'knowledges' need to be considered to extend heterogeneity bwithin processes of collaboration and dialogue in ESD. In this regard, our understanding of 'indigenous peoples' aligns with that of Breidlid (2013), and thus includes those with a shared experience of domination, that "originates with and is perpetuated by, their contact with Western hegemonic epistemology" (Breidlid, 2013, p. 31). Thus, overall ESD should highlight the connectivity of humans and non-humans, including organisms such as animals and plants (Farrell, 2013) and focus on interconnectedness, embeddedness and interdependencies within and across ecosystems.

We could use bees, drawing on the knowledge of foresters, biologists, economists and on Paris' rooftop bee-keeping revolution (Clarke, 2012), to exemplify the high interconnectedness of everything on this planet, highlighting that everyone and everything interacts. Through the act of pollination, bees are not only closely connected with plants, humans are connected to bees too. We need them to cultivate our crops. We also enjoy as much as other species nuts, berries, fruits, not to mention nutritious honey from bees. Other animals are connected to bees, acting as parasites, living within their nest or 
nourishing from their brood, pollen or wax (Bradbear, 2009). In the same way, there is a connection of bees and trees. High trees in forests are a common nesting place for bees. Bees improve the regeneration of trees and the conservation of the forest's biodiversity through the process of pollination (Bradbear, 2009). If natural forests disappear, bees disappear and vice versa. If the bees are extinguished, we may experience a collapse of our food supply chain and, therefore, of our economy as we know it today. As a result, we come to understand that agriculture, through bees, is as much connected to the forests as economy.

There is no superior position within the rhizome, as within the realm of the rhizome everyone and everything can be an actor (Deleuze \& Guattari, 1987). The rhizomatic principle of heterogeneity thus demands openness to knowing different disciplines and learners. Diversity should be reflected in ESD in order to make learners aware of the interconnectedness and heterogeneity of earth and to acquire the type of understanding essential to make sense of sustainability.

\section{Active and Participatory Learning and Multiplicity}

In this section, we examine how processes of active and participatory learning (Tilbury, 2011) align with the rhizomatic principle of multiplicity (Deleuze \& Guattari, 1987). Assemblages within the rhizome contain connections between multiplicities, formed to enable the multiplicity to become some form of functional apparatus. For instance, the self is a multiplicity with several elements, such as organs, mind, gender etc. The heart itself is a multiplicity containing various elements, such as heart cells, aorta, left atrium etc. The heart is a multiplicity, that together with the self, forms the functional apparatus and assemblage that constitutes the human being. Sustainability is also a multiplicity by nature. The principle of multiplicity of the rhizome makes it impossible to define a centre (humans), elements or a hierarchy (of elements) "there are no points or positions in a rhizome, such as those found in a structure, tree or root" (Deleuze \& Guattari, 1987, p. 8). The "increase in the dimensions of a multiplicity that necessarily changes in nature as it expands its connections" (Deleuze \& Guattari, 1987, p. 8 ) indicates that the nature of sustainability can change entirely as all participants or aspects of sustainability are in constant flux. Thus, applying the principle of multiplicity to ESD enables us to understand progress in understanding or acting on sustainability as it underpins the progressive growth, expansion, transformation of knowledge and understanding.

The processes of active and participatory learning are necessary conditions for growth in dimensions of the multiplicities within ESD. In the context of sustainability education, this growth in multiplicity demands a perspective of the world through interchangeable lenses of ecologies. Guattari (1989) names three ecologies: the mental, the socius and the environment or, as Le Grange (2011) interpreted, the ecologies of self, society and nature. Rather than focusing on the constitution of one ecology and teaching 'about' or 'for' it, we should focus on the contradiction, discrepancies and oppositions between these ecologies (Guattari, 1989). This may activate isolated and heterogeneous perspectives, nurture individual cultures and simultaneously foster the imagination of new forms of thinking and practices. In turn, it may also encourage the imagination of a state order in which singularity, exceptions and rarity coexist (Guattari, 1989) to name but a few creative shades of multiplicity. For instance, as our mental 
ecology is often dominated by arborescent ways of thinking, we tend to make sense of the social through hierarchy expressed by classes. Furthermore, we humans often assume a superior position over nature. This is exemplified through our urban living conditions, which not only excludes other life of this planet, allocating minor areas for nature, but

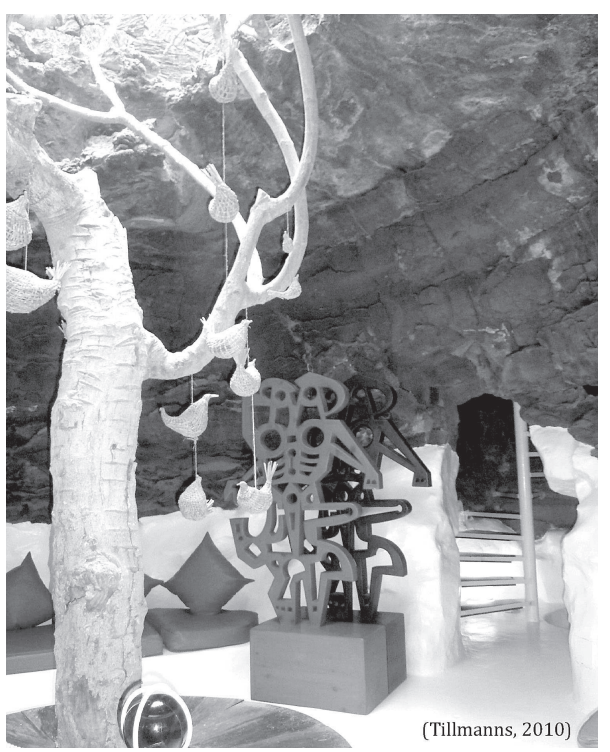

Figure 2. César Manrique's residence is dominated by unsustainable architecture, whose construction requires the abuse of natural resources and, at a later stage, consumes high volumes of electricity for lightning, heating and cooling.

However, within these three ecologies lie capacities for creativity. For instance, the artist and architect César Manrique "felt true nostalgia for the real meaning of things. For the pureness of people. For the bareness of my landscape and for my friends" (César Manrique Foundation, 2014). This inspiration influenced the construction of his house in his homeland Lanzarote that connects his work of art and architecture with nature. The residence was built on top of a volcanic trail, the lower level of the house is positioned within the natural formation of five volcanic bubbles that are used for living spaces (Figure 2). The outside of the residence has influenced the traditional architecture of the island of Lanzarote. The island is still today characterised by the harmony of art, natural environment and Lanzarote's culture, and Manrique's work - found throughout Lanzarote - is an expression of such harmony.

\section{Curriculum, Teaching, Learning Innovation and Signifying Rupture}

We now need to examine how processes that innovate curriculum, teaching and learning (Tilbury, 2011) align with the rhizomatic principle of signifying rupture (Deleuze \& Guattari, 1987). The principle of signifying rupture indicates that a rbizome can be broken or disrupted at any point but it does not get damaged and will regenerate (Deleuze \& Guattari, 2009). My first visit to César Manrique's house exemplifies such a rupture. Being physically in a house that was built in harmony with nature, disrupted and consequently expanded my imagination of housing. Planet earth also provides many illustrations of this principle of signifying rupture.

Let us imagine for a moment the earth as a rhizome. As we know, there is a tendency of humans to imagine the end of the world - particularly through cinema - as an armageddon (Dawson, 2013). Let us consider a nuclear holocaust. Would it mean the end of planet earth? It would probably mean the end of many species, including humans, but earth seen as a rhizome would begin again or continue as, for instance, we know that cockroaches are radiation resistant (Wright, 2010). The nuclear holocaust would be a signifying rapture. For instance, history taught us that the extinction of the dinosaurs or of ancient civilisations did not terminate life on this planet. Even if a nuclear holocaust 
or global warming do become 'signifying ruptures', causing destruction of our living spaces, it may not imply the end of the planet, but rather a further challenge to our adaptability as a species living on this planet. Within sustainability education, there is a worthy focus on preventing such catastrophes, but very often the approach taken is human-centric in nature and doesn't always critically consider the significance of these ruptures beyond that which impacts the wants or needs of humanity on planet earth.

Returning to ESD, educators and learners need to be more aware that any existing framework or definition of sustainability is incomplete, as sustainability is a fluid, complex concept, which does not lend itself to being generalised. Rhizomatic principles enable us to think of sustainability as being in constant flux and transformation. They allow us to relate as much new meaning as new knowledge, through the binary process of deterritorialisation current understanding/reterritorialision of novel understanding. Processes which innovate curriculum as well as teaching and learning experiences (Tilbury, 2011) entail in a broader sense, changing mindsets, fostering active and interactive engagement, questioning social assumptions and dominant ways of thinking (Tilbury, 2011).

The pedagogy of ESD should enable transversal thinking (Guattari, 1989) which moves beyond learners' current abilities for critical thinking (Huckle \& Sterling, 1996) and linking knowledge to the fate of humanity (Nikolopoulou, 2010). A basic approach to the development of transversal thinking could be teaching about the universe and the histories of the world, before focusing on national histories (Nikolopoulou, 2010). ESD should also encourage the imagination of a post media age and raise awareness of capitalist societies depicted by mass media (Guattari, 1989). ESD should also consider the re-education of 'holders of power'. They too would benefit from an understanding of the necessity of evaluating profits or 'growth interest' having in mind international interests of humanity as a whole, and acting according to a reformulated definition of wealth and nature (Nikolopoulou, 2010). The 2011 study at the Swiss Federal Institute of Technology in Zurich offers a useful starting point to examine the power dynamics in the world and the necessity of applying a broader and reformulated perspective on wealth. While mapping ownerships among the world's transnational corporations, this study revealed a core of 1318 companies with interlocking ownerships, and, when the web of ownership was unravelled, they discovered a 'super-entity' of 147 corporations that control 40 per cent of the total wealth (Vitali, Glattfelder, \& Battiston, 2011).

\section{Whole System Engagement, Cartography and Decalcomania}

We now examine how processes that engage the whole system (Tilbury, 2011) are aligned with rhizomatic principles of cartography and decalcomania (Deleuze \& Guattari, 1987). A rhizome has no beginning, ending, centre or periphery. It has a very complex structure, thus making it unclear from which element or place the next will be reached, and how to get there (Deleuze \& Guattari, 1987). A rhizome can be considered as a map and is distinct from what one might consider tracing. Tracing follows an arborescent thought where tree-type (hierarchical) logic reproduces what already exist, following a given path from beginning to end. Mapping is generative. Mapping is open to various manifestations. It is created on the basis of fostering new connections, proceeding from any point, picking up from the middle and creating one or many paths (Deleuze \& Guattari, 1987), thus also coinciding with the process of decalcomania, a technique 
that creates images or paintings largely by chance. Unlike tracing, that aims to reproduce or describe structures, mapping constructs connections, removes blockages and creates structures.

The problem in ESD to date is that the focus has been on tracing as opposed to mapping ESD landscape. Since sustainability has been introduced within the mainstream discourse, the reliance on tracing of its elements and its structure intensified. The pillars of sustainability defined by the United Nations Educational, Scientific and Cultural Organisation are an attempt to describe the structure of sustainability and now act as guiding principles for ESD at a global level. The reproduction of these pillars can be noticed in various disciplines connected with sustainability, not to mention its application within ESD. Furthermore, the tendency towards prioritisation of one pillar over the other represents a major blockage and an opposing perspective to the rhizomatic approach. Rather than conforming to a suitable definition, it is time to experiment, to learn from and to share these experiences in order to gain a novel and fluid understanding of the meaning of sustainability. Sustainability does not need a definition. Crucial elements that supposedly contribute to the understanding of sustainability can never be fully identified. Similarly, sustainability cannot be assigned to specific disciplines or be a pure matter of teaching and learning. Besides re-imagination of the purpose of education and the relationship between teachers and learners (Carp, 2013), holistic approaches throughout the whole institution and educational system (Tilbury, 2011), in which, for instance, students are likewise included in management decisions as much as in curricula design (Bruskotter, Hitzhusen, Wilson, \& Zwickle, 2013) exemplify processes which engage the whole system, as promoted by Tilbury (2011).

\section{Conclusions}

The biosphere that we inhabit is interconnected in many different ways; we as human beings make contact, interact and strive to understand this planet at physical and metaphysical levels. Perhaps we can better understand and learn about sustainability by re-conceptualising the earth in terms of rhizomatic constructs and principles. We can start this process by learning from the wisdom of plants, who, according to Deleuze and Guattari (1987), connect to multiple organisms and entities:

even when they have roots, there is always an outside where they form a rhizome with something else - with the wind, an animal, human beings (and there is also an aspect under which animals themselves form rhizomes, as do people, etc.) (p. 11).

Our downfall has been to have taken a human-centric approach to understanding our world; one in which we have taken human-centric approaches to understanding our place and role within planet earth. It has resulted in the depletion of many of our natural resources, damage to our environment and significant risk to the long-term sustainability of our biosphere.

The re-conceptualisation of ESD as rhizome or rhizomatic can foster an ontological shift towards perceiving the nature of reality as complex multiplicities, and, in so doing, the rhizome has the potential to inspire educators and learners alike to become more critically aware of the interconnectivity of, and disruptive influences within, sustainability, above and below the surface. Within ESD, we want to support the development of 
change agents. This process of inspiring and enabling change agency necessitates the development of transformative learning and of an enterprising mindset for learners. Deleuze and Guattari's work on rhizomatic principles provides a useful frame for developing such mindsets. As outlined in this paper, the weaving of rhizomatic principles within the processes of ESD can positively impact on educating for sustainability.

ESD needs also to support 'becoming other', resisting "the arrogance of certainty and self sufficient knowledge" (Cilliers, 2005, p. 265) and recognise the importance of learning sustainability from other species or indigenous people (Pigem, 2007; Wals, 2012). Chandra (2014) also points out that indigenous knowledge needs to be recognised to tackle ecological issues. In this regard, the alignment of processes of collaboration and dialogue, as detailed by Tilbury (2011), in conjunction with the rhizomatic principles of connection and heterogeneity (Deleuze \& Guattari, 1987) within ESD, generates a viable pathway for responding to and interacting with differing perspectives from transdisciplinary, intercultural and varied contexts.

And what of the rhizomatic constructs of war machines and lines of flight? There is a real need for change to be effected within ESD - the evidence to date is that while some progress has been made in the DESD (2005-2014), more needs to be done. The rhizomatic construct of the war-machine presents us with a tool to tackle issues of sustainability. It offers emancipation from conformist understandings and approaches within ESD, by shifting neoliberal type ontologies and resisting the global capitalist power of states. In this regard, further research needs to be undertaken to map how rhizomatic constructs, such as assemblages, multiplicities, war machines and lines of flights) evolve within real-world ESD settings. Only then can the synergies between rhizomatic principles and the six processes for effective ESD (as outlined by Tilbury, 2011) be examined and the extent to which our interventions in ESD support positive transformations and change agency for sustainability be assessed.

\section{References}

Avolos, B., \& Winslade, J. (2010). Education as a 'line of flight. Explorations: An E-Journal of Narrative Practice, 1, 70-77.

Barber, B., \& Rousseau, L. (2013). The living home: Building it into the curriculum. In L. F. Johnston (Eds.), Higher education for sustainability: Cases, challenges, and opportunities from across the curriculum (pp. 169-182). New York: Routledge.

Bradbear, N. (2009). Bees and their role in forest livelihoods: A guide to the services provided by bees and the sustainable harvesting, processing and marketing of their products. Retrieved July 29, 2014, from ftp://ftp.fao.org/docrep/fao/012/i0842e/ i0842e00.pdf

Breidlid, A. (2013). Education, indigenous knowledges, and development in the global south. New York: Routledge.

Bruskotter, J. T., Hitzhusen, G. E., Wilson, R. S., \& Zwickle, A. (2013). Understanding student environmental interests when designing multidisciplinary curricula. In L. F. Johnston (Eds.), Higher education for sustainability: Cases, challenges, and opportunities from across the curriculum (pp. 29-44). New York: Routledge.

Carp, R. M. (2013). Toward a resilient academy. In L. F. Johnston (Eds.), Higher education for sustainability: Cases, challenges, and opportunities from across the curriculum (pp. 223-237). New York: Routledge. 
César Manrique Foundation. (2014). Biography. Available from http://www.cesar manrique.com/biografia_i.htm

Chandra, D. V. (2014). Re-examining the importance of indigenous perspectives in the western environmental education for sustainability: "From tribal to mainstream education". Journal of Teacher Education for Sustainability, 16(1), 117-127.

Cilliers, P. (2005). Complexity, deconstruction and relativism. Theory, Culture \& Society, $22(5), 255-267$.

Clarke, P. (2012). Education for sustainability: Becoming naturally smart. New York: Routledge.

Dawson, A. (2013). Introduction to focus: Apocalypse now. American Book Review, $34(2), 3$.

DeLanda, M. (2006). A new philosophy of society: Assemblage theory and social complexity. London: Bloomsbury.

Deleuze, G., \& Guattari, F. (1987). A thousand plateaus: Capitalism and schizophrenia. Minneapolis, MN: The University of Minnesota Press.

Deuchars, R. (2011). Creating lines of flight and activating resistance: Deleuze and Guattari's war machine. Retrieved, August 3, 2014, from http://www.victoria.ac.nz/ atp/articles/pdf/Deuchars-2011.pdf

Escrigas, C., Granados Sanchez, J., Hall, B., \& Tandon, R. (2014). Editors' introduction: Knowledge, engagement and higher education contributing to social change. In Global University Network for Innovation (Eds.), Higher education in the world: Knowledge, engagement and higher education: Contributing to social change (pp. xxxi-xxxix). Basingstoke: Palgrave, MacMillan.

Farrell, J. J. (2013). The moral ecology of everyday life. In L. F. Johnston (Eds.), Higher education for sustainability: Cases, challenges, and opportunities from across the curriculum (pp. 154-168). New York: Routledge.

Guattari, F. (1989). The three ecologies. New Formations, 8, 131-147.

Huckle, J., \& Sterling, S. (1996). Education for sustainability. London: Earthscan Routledge.

Le Grange, L. (2011). Sustainability and higher education: From arborescent to rhizomatic thinking. Educational Philosophy and Theory, 43(7), 742-754.

Nikolopoulou, A., Abraham, T., \& Mirbagheri, F. (2010). Education for sustainable development: Challenges, strategies and practices in a globalizing world. New Delhi: SAGE Publications India Pvt Ltd.

Pigem, J. (2007) (Ed.). Faith-based organizations and education for sustainability. Retrieved July 25, 2014, from http://www.arcworld.org/downloads/Barcelona \% 20Report.pdf

Tilbury, D. (2011) Education for sustainable development: An expert review on processes and learning for ESD. Retrieved July 20, 2014, from http://unesdoc.unesco.org/ images/0019/001914/191442e.pdf

Vitali, S., Glattfelder, J. B., \& Battiston, S. (2011). The network of global corporate control. Plos ONE, 6(10), 1-6.

Wals, A. E. J. (2012). Shaping the education of tomorrow: 2012 full-length report on the UN decade of Education for Sustainable Development. Retrieved August 5, 2014, from http://www.desd.org/UNESCO\%20report.pdf

Wals, A. E. J. (2014). Sustainability in higher education in the context of the UN DESD: A review of learning and institutionalization processes. Journal of Cleaner Production, 62, 8-15. 
Wright, A. (2010). Backpack-wearing cockroaches to detect radiation. National Defense, 94(676), 17.

Correspondence concerning this paper should be addressed to Tanja Tillmanns, a PhD candidate, School of Education Studies, Dublin City University, Glasnevin, Dublin 9, Ireland. Email: tillmanns.tanja@gmail.com 